\title{
STRATEGI COPING PEREMPUAN KORBAN PELECEHAN SEKSUAL DITINJAU DARI TIPE KEPRIBADIAN "EYSENCK"
}

\author{
Devi Jatmika
}

\author{
Fakultas Psikologi \\ Universitas Bunda Mulia \\ Jalan Lodan Raya No. 2, Ancol \\ Jakarta Utara 14430 \\ djatmika@bundamulia.ac.id
}

\begin{abstract}
Sexual harassment occurs everywhere, anytime, against especially toward women. This study attempts to find the difference in sexual harassment coping strategies' based on Eysenck personality type (extrovert-introvert). There are two kinds of coping strategies: a) problem focused coping and b) emotion focused coping. The instrument in this research is a questionnaire that was given to young adulthood women (20-40 years old). Subjects in this research are 192 female. The mean score of problem focused coping dimension is $42.14(S D=7.64)$ and the mean score of emotion focused coping dimension is 37.02 ( $S D=4.19)$ on women who have introvert personality type. The mean score of problem focused coping dimension is $48.60(S D=6.69)$ and the mean score of emotion focused coping dimension is $38.02(S D=4.02)$ on women who have extravert personality type. Research hypothesis was denied; $c^{2}(1)=0.537$, sig/p $0.449>0.05$ thus there is no difference in women coping strategies as victim of sexual harassment.
\end{abstract}

Keywords: coping strategies; sexual harassment; personality type (extravertintrovert).

\begin{abstract}
Abstrak
Pelecehan seksual dapat terjadi dimana saja, setiap waktu dan terutama terhadap perempuan. Penelitian ini bertujuan untuk mengetahui perbedaan strategi coping perempuan korban pelecehan seksual ditinjau dari tipe kepribadian "Eysenck" (ekstrovertintrovert). Strategi coping meliputi dua jenis yaitu: a) problem focused coping dan b) emotion focused coping. Penelitian ini menggunakan instrumen berupa kuesioner yang diperuntukkan bagi perempuan dewasa muda (20-40 tahun). Subyek penelitian sebanyak 192 orang. Perempuan bertipe kepribadian introvert memiliki nilai rata-rata pada dimensi problem focused coping 42.14 ( $\mathrm{SD}=7.64$ ), sementara dimensi emotion focused coping memiliki nilai rata-rata $37.02(\mathrm{SD}=4.19)$. Perempuan bertipe kepribadian ekstrovert memiliki nilai rata-rata pada dimensi problem focused coping $48.60(\mathrm{SD}=6.69)$ sementara dimensi emotion focused coping memiliki nilai rata-rata $38.02(\mathrm{SD}=4.02)$. Hipotesis penelitian tidak terbukti, $\chi^{2}(1)=0.537, \mathrm{sig} / \mathrm{p} 0.449>0.05$ yang berarti tidak ada perbedaan strategi coping pada perempuan korban pelecehan seksual bertipe kepribadian ekstrovert dan tipe kepribadian introvert.
\end{abstract}

Kata kunci: strategi coping; pelecehan seksual; tipe kepribadian (ekstrovertintrovert). 


\section{PENDAHULUAN}

Pelecehan seksual berasal dari kata “'pelecehan' dan ' seksual'. Menurut Kamus Umum Bahasa Indonesia edisi ke-3 (Alwi, Lapoliwa, Sugono, Kridalaksana, Adiwimarta, Suratman, Nainggolan, Sutiman, Murniah, Patoni, Burhabudin, Gaffar, Hanid, Haryanto \& Sutini, 2003), kata dasar 'leceh' berarti hina, tidak berharga, dan bernilai rendah. Oleh karena itu, pelecehan dapat diartikan sebagai proses menjadikan sesuatu menjadi hina dan tidak berharga. Sedangkan 'seksual' mengandung arti halhal yang menyangkut seks atau jenis kelamin, hal yang berkenaan dengan perkara persetubuhan antara pria dan wanita (Swasti, Pasaribu, \& Gusman, 2006). Berdasarkan pengertian tersebut, pelecehan seksual berarti suatu bentuk penghinaan atau memandang rendah seseorang karena hal-hal yang berkenaan dengan seks, jenis kelamin atau aktivitas seksual antara pria dan wanita (Kusmana, 2005). Menurut Papu (2002), segala macam bentuk perilaku yang berkonotasi atau mengarah kepada hal-hal seksual yang dilakukan secara sepihak dan tidak diharapkan oleh orang yang menjadi sasaran sehingga menimbulkan reaksi negatif seperti malu, marah, benci, tersinggung pada diri individu yang menjadi korban pelecehan tersebut tergolong dalam pelecehan seksual.

Di Indonesia istilah pelecehan seksual dipakai setelah banyak kasus ditampilkan oleh kalangan pers. Kasus-kasus pelecehan seksual mulai banyak dibicarakan, tetapi penelitian bersifat empirik masih relatif sedikit (Kusmana, 2005). Sebuah survei yang dilakukan oleh tim peneliti kekerasan terhadap perempuan di Daerah Istimewa Yogyakarta (DIY) membagi tindak kekerasan dalam tiga kategori, yaitu: (a) kategori ringan (terdiri dari ditatap penuh nafsu, disenyumi nakal, disiuli atau dikomentari kata yang berbau seks, diajak berbicara cabul, dan ditelepon seks); (b) kategori sedang (terdiri dari diintip dengan maksud seksual, dicolek, diraba atau digerayangi, dipaksa memegang organ tubuh pelaku, dicuri cium, dipertontonkan alat kelamin, dan dipertontonkan benda atau foto porno); dan (c) kategori berat (terdiri dari usaha perkosaan dan perkosaan). Hasil survei tersebut menemukan dari 542 reponden sebanyak 4,6\% pernah mengalami kekerasan seksual yang cukup berat, $75,1 \%$ mengalami kekerasan tingkat sedang, dan 91,7\% pernah mengalami kekerasan tingkat ringan (Abdullah, Dzuhayatin, \& Pitaloka, 2001).

Menurut Kusmana (2005), penyebab mendasar pelecehan seksual sama dengan dasar terjadinya diskriminasi, penindasan dan ketidakadilan yang dialami oleh kaum perempuan (kekerasan dalam rumah tangga, diskriminasi upah, perkosaan, pelacuran, dan perdagangan perempuan). Penyebab utamanya adalah adanya kekuasaan dan ketidaksetaraan ekonomi serta pandangan seksis yang meluas dalam masyarakat, yaitu posisi kaum laki-laki dianggap lebih tinggi daripada perempuan. Pandangan ini kemudian membenarkan pemikiran bahwa tubuh perempuan adalah objek seksual.

Komisi Nasional (Komnas) Perempuan mencatat kasus-kasus kekerasan terhadap perempuan dan menyatakan bahwa dengan mempelajari data yang ada, rentang usia 25-40 tahun merupakan usia yang paling rentan sebagai korban maupun pelaku kekerasan (40\%-50\%), meskipun tidak ada uji statistik dalam pengolahan data ini (Komisi Nasional Anti Kekerasan terhadap Perempuan, 2005). Pada rentang usia ini merupakan masa-masa puncak semangat, daya tahan, tenaga dan semangat bagi perempuan untuk melakukan tugas-tugas perkembangannya. Oleh karena itu, penelitian ini akan lebih memfokuskan pada subjek perempuan berusia 20-40 tahun (Hurlock, 1998).

Pada perempuan yang mengalami pelecehan pertama kalinya, peristiwa itu seringkali diabaikan, berusaha mengartikannya bukan sebagai bentuk pelecehan, dan menghindar. Cara yang lebih banyak digunakan ini disebut sebagai strategi tidak langsung (indirect strategies of coping) namun tidak begitu efektif. Sementara strategi langsung (direct strategies of coping) yang lebih sedikit dilakukan korban seperti melawan, menyuruh atau meminta pelaku untuk menghentikan, mengancam akan memberitahu 
orang lain, melaporkan ke pihak berwajib lainnya, dan memukul pelaku (Gutek \& Koss dalam O’Toole \& Schiffman, 1997).

Larse (dalam Pervin, 1996) menyebutkan bahwa perbedaan kepribadian individu membuat individu memberikan respon emosional yang berbeda. Karakteristik mendasar dari kepribadian terletak pada dimensi ekstrovert-introvert (dimensi E) dan dimensi neurotic-stable (dimensi N). Eysenck meyakini bahwa setiap orang pasti berada pada suatu posisi dalam kontinum kedua dimensi tersebut (Abidin \& Suyasa, 2003). Masing-masing orang bukanlah ekstrovert atau introvert sejati, namun lebih pada kecenderungan kontinum dari tipe kepribadian ekstrovert dan introvert (Posella, 2006).

Eysenck mengemukakan bahwa seseorang yang ekstrovert dikenal memiliki kepribadian optimis, terbuka, senang bergaul, aktif, riang, mempunyai banyak teman, cenderung agresif, mudah kehilangan kesabaran, kurang dapat mengontrol perasaannya dengan baik dan impulsif. Introvert adalah kebalikan dari ekstrovert, yaitu pendiam, terkontrol, berhati-hati, introspektif, reflektif, jarang berperilaku agresif, tidak mudah hilang kesabaran, tidak menyukai pengambilan keputusan yang impulsif, dan lebih menyukai kehidupan yang teratur daripada kehidupan yang penuh tantangan dan resiko (Pervin \& John, 1997; Abidin \& Suyasa, 2003). Perbedaan dalam kepribadian ekstrovert dan introvert ini mempengaruhi cara orang dalam menghadapi situasi sekitar secara berbeda.

Cara seseorang dalam mengatasi masalah disebut dengan coping. Cara mengatasi masalah setiap individu bergantung pula pada cara pandang/penilaian terhadap masalah yang dihadapi. Suatu masalah dapat dinilai sebagai tantangan, melukai perasaan, menimbulkan perasaan kehilangan, atau sebagai ancaman (Lazarus, 1976). Lazarus (1984) membedakan dua kategori coping, yakni problem-focused coping (active coping) dan emotion-focused coping (passive coping). Problem-focused coping adalah strategi coping aktif yang digunakan untuk mengurangi kecemasan dengan menghadapi situasi atau masalah sebenarnya. Emotion-focused coping adalah strategi coping aktif secara emosi dan kognitif (menggunakan perasaan dan pikiran) ketika masalah atau peristiwa yang membuat stres muncul. Hal ini dilakukan untuk mengurangi kecemasan (emosi) seseorang terkait dengan situasi yang terjadi. Bentuk dari emotion-focused coping ini seperti menjaga jarak, menghindar, dan melarikan diri (Pervin, 1996; Posella, 2006).

Gallaghar (dalam Posella, 2006) menemukan bahwa perilaku coping pada introvert berbeda dengan ekstrovert. Pada kenyataannya, coping berhubungan dengan kepribadian. Ekstrovert berkorelasi positif dengan strategi coping aktif dengan menghadapi situasi (Baoyong dalam Posella, 2006). Halammandaris dan Power (dalam Posella, 2006) menemukan sebaliknya bahwa individu dengan tipe kepribadian introvert berkorelasi dengan strategi aktif yang berfokus pada emosi, serta bertujuan mengurangi stres. Lazarus dan Folkman (1984) menyatakan adanya kesesuaian antara situasi dan strategi coping. Problem focused coping lebih adaptif dalam situasi yang dapat diubah sedangkan emotion focused coping lebih tepat ketika situasi berada di luar kontrol.

Berdasarkan dari uraian sebelumnya, penelitian ini bertujuan untuk mengetahui apakah terdapat perbedaan strategi coping terhadap peristiwa pelecehan seksual, pada perempuan dewasa muda antara tipe kepribadian ekstrovert dengan introvert. Penelitian ini juga bertujuan untuk mengetahui strategi coping yang digunakan seseorang menurut tipe kepribadiannya dalam mengatasi peristiwa pelecehan seksual. 


\section{METODE}

\section{Partisipan.}

Kriteria subjek penelitian ini adalah perempuan usia dewasa muda dengan rentang usia 20-40 tahun dan pernah menjadi korban perilaku pelecehan seksual dalam bentuk apapun. Tingkat pendidikan akhir subyek dibatasi minimal adalah Sekolah Menengah Umum (SMU). Pengambilan subyek dengan rentang usia 20-40 tahun berdasarkan data dari Komnas Perempuan (2006) menyebutkan bahwa rentang usia antara 25-40 tahun merupakan usia yang paling rentan menjadi korban maupun pelaku kekerasan. Partisipan penelitian ini adalah mahasiswi-mahasiswi di beberapa kampus, karyawati-karyawati dari dua perusahaan swasta yang terletak di daerah Jembatan Tiga (perusahaan A dan E) dan sebuah perusahaan swasta di daerah Sudirman (perusahaan G), perempuan yang bekerja di tempat bimbingan belajar dan preschool, serta di tempat umum sebuah mal M di Pluit.

Desain. Desain penelitian yang digunakan adalah penelitian kuantitatif non eksperimental yang ditujukan untuk mengukur perbedaan.

\section{Prosedur Penelitian.}

Tahap pertama dari penelitian ini adalah penulis mencari fenomena dari lingkungan social yang diperoleh dari topik bahasan dalam sebuah surat kabar. Kemudian, penulis menggali aspek psikologis yang dapat diteliti dari fenomena tersebut dan membuat tema penelitian. Berdasarkan teori-teori dan data-data statistik yang didapatkan, penulis menyusun hipotesis penelitian dan membuat rancangan alat ukur untuk mengukur dua variabel penelitian yaitu variabel tipe kepribadian dan variabel strategi coping terhadap pelecehan seksual. Rancangan alat ukur ini diuji validitas isi oleh dua dosen pembimbing, untuk selanjutnya dilakukan uji coba/ try out. Uji coba kuesioner strategi coping dan tipe kepribadian diberikan pada 34 sampel setelah itu dilanjutkan dengan analisis butir dan uji reliabilitas menggunakan SPSS 13.0 for Windows.

Hasil uji coba menunjukkan adanya kecenderungan social desirability yang disebabkan oleh kesalahan konsep saat merancang alat ukur kepribadian. Penulis kemudian memperbaiki alat ukur untuk tipe kepribadian dan disebarkan kembali kepada 50 sampel. Setelah itu, peneliti melakukan analisis hasil butir dan uji reliabilitas kembali dengan SPSS 13.0 untuk memperoleh butir-butir yang valid dari try out alat ukur tipe kepribadian Setelah melewati proses uji validitas dan reliabilitas, maka kedua alat ukur siap digunakan untuk pengambilan data penelitian.

Setelah persiapan penelitian selesai, kuesioner yang telah lengkap dibagikan kepada sampel penelitian sebanyak 200 orang perempuan dewasa muda berusia 20-40 tahun di Jakarta, yakni daerah Jembatan Tiga, Sudirman, dan Pluit. Pengambilan data berlangsung dari tanggal 1 Juni-15 Juli 2007. Setelah pengambilan data selesai, ditemukan 8 sampel yang dianggap gugur atau tidak dapat disertakan datanya dalam penelitian karena tidak mengisi lengkap data kontrol pelecehan seksual, tidak mengerjakan sesuai dengan petunjuk instruksi, dan tidak menjawab kuesioner sampai selesai. Total sampel yang memenuhi syarat sebanyak 192 orang.

\section{Teknik analisis \& alat ukur.}

Kuesioner dalam penelitian ini disusun sendiri oleh peneliti. Kuesioner pertama mengukur bentuk-bentuk pelecehan yang pernah dialami oleh subyek dengan petunjuk pengisian berupa "Ya" atau "Tidak". Subyek pertama-tama harus menjawab "Ya" (pernah) atau "tidak" (tidak pernah) mengalami tiap pernyataan bentuk pelecehan seksual. Kemudian jika "Ya" (pernah) subyek harus mengisi kolom selanjutnya yang menyatakan apakah subyek terganggu dengan perlakuan tersebut 
atau tidak terganggu. Subyek yang merasa terganggu dengan perlakuan tersebut berarti telah menjadi korban pelecehan seksual. Subyek juga dapat mengisi dengan memberi lingkaran dari 11 dampak psikologis yang dirasakan subyek karena peristiwa pelecehan seksual tersebut dan menambah dampak psikologis yang dirasakan dengan menulis pada pilihan lainnya. Begitu pula, pada dampak fisik yang dirasakan subyek. Subyek dapat memilih lebih dari satu dampak psikologis dan dampak fisik yang dirasakan. Kuesioner ini dibuat agar data yang menunjukkan bahwa subyek pernah menjadi korban pelecehan seksual lebih akurat selain itu, data ini dapat dijadikan gambaran statistik (survei) pelecehan seksual dalam penelitian.

Alat ukur dari strategi coping terhadap pelecehan seksual dan tipe kepribadian disusun dengan menggunakan skala Likert mempunyai gradasi dari sangat setuju (favorable) sampai dengan sangat tidak setuju (unfavorable). Kuesioner kedua yaitu sebuah kuesioner yang berisi butir-butir pernyataan yang menunjukkan strategi coping yang digunakan terhadap peristiwa pelecehan seksual. Jumlah butir strategi coping yang sudah valid berjumlah 25 butir. Kuesioner ke tiga yaitu alat ukur kepribadian dimana setelah uji validitas dan realibilitas terdiri dari 42 butir. Pada teori Eysenck, tipe kepribadian introvert pada dasarnya merupakan kebalikan dari ekstrovert. Oleh karena itu, semakin tinggi skor subyek, maka semakin tinggi indikator-indikator yang mengarah pada tipe kepribadian ekstrovert, dan sebaliknya semakin rendah skor yang diperoleh subyek semakin mengarah pada tipe kepribadian introvert.

\section{Pengukuran.}

Batasan operasional. Alat ukur strategi coping disusun sendiri oleh penulis berdasarkan skala coping (Folkman, Lazarus, Dunkel-Shetter, DeLongis \& Gruen, 1986) Problem focused coping terbagi menjadi tiga indikator. Confront coping yaitu perilaku asertif, melibatkan agresi atau pengambilan resiko untuk merubah situasi, dengan pertanyataan item seperti "Saya menegur pelaku pelecehan untuk menghentikan tindakannya" $(\alpha=.805)$. Seeking sosial support yaitu berusaha mencari dukungan informasi dan emosional, dengan contoh aitem "Saya menceritakan peristiwa pelecehan seksual yang saya alami pada orang-orang terdekat saya $(\alpha=.0 .62)$. Plan problem solving yaitu menganalisa situasi untuk menghasilkan solusi dan kemudian mengambil tindakan langsung untuk memperbaiki masalah, dengan contoh pernyataan aitem "Saya berusaha mencari jalan terbaik untuk menghadapi peristiwa pelecehan yang saya alami” $(\alpha=.0 .73)$.

Strategi emotion focused coping terdiri dari lima indikator. Self control berarti usaha untuk mengontrol perasaan diri sendiri, dengan contoh aitem "Saya berusaha mengendalikan emosi ketika mengalami pelecehan seksual" $(\alpha=.059)$. Distancing berarti membuat usaha kognitif untuk melepaskan diri sendiri dari situasi atau membuat terlihat positif, dengan aitem: "Saya berbicara pada diri saya bahwa peristiwa pelecehan seksual itu tidak penting untuk dicemaskan". Escape-avoidance yang berarti berpikir penuh harapan (wishful thinking) mengenai situasi atau membuat tindakan untuk melarikan diri atau menghindar, dalam alat ukur dinyatakan dengan aitem: "Saya mencoba melupakan peristiwa pelecehan seksual itu dengan melakukan kegiatan-kegiatan yang menyenangkan" $(\alpha=.56)$. Accepting responsibility berarti mengakui peran diri seseorang dalam suatu masalah, dengan aitem: Peristiwa pelecehan seksual yang saya alami adalah tanggung jawab saya untuk mengatasinya" $(\alpha=0.7)$. Positive appraisal yakni berusaha untuk mencari arti positif dari kejadian dengan berfokus pada pertumbuhan pribadi: "Saya meninjau ulang kejadian pelecehan seksual yang saya alami dengan cara lebih positif" $(\alpha=0.69)$. 
Tabel 1. Hasil Reliabilitas Alat Ukur Strategi Coping

\begin{tabular}{|c|c|c|c|c|c|c|}
\hline \multirow[t]{2}{*}{ Dimensi } & \multirow[t]{2}{*}{ Indikator } & \multicolumn{2}{|c|}{ Reliabilitas $(\alpha)$} & \multicolumn{2}{|c|}{ Banyak butir } & \multirow[t]{2}{*}{ Butir reliabel } \\
\hline & & Sebelum & Sesudah & Sebelum & Sesudah & \\
\hline & & \multicolumn{2}{|c|}{ Analisis Butir } & \multicolumn{2}{|c|}{ Analisis Butir } & \\
\hline \multirow{3}{*}{$\begin{array}{l}\text { Problem } \\
\text { focused } \\
\text { coping }\end{array}$} & Confront coping & 0.805 & 0.805 & 4 & 4 & $3,7,19,25$ \\
\hline & $\begin{array}{l}\text { Plan problem } \\
\text { solving }\end{array}$ & 0.625 & 0.625 & 4 & 4 & $1,10,15,16$ \\
\hline & $\begin{array}{l}\text { Seeking social } \\
\text { support }\end{array}$ & 0.733 & 0.733 & 4 & 4 & $4,9,13,20$ \\
\hline \multirow{5}{*}{$\begin{array}{l}\text { Emotion } \\
\text { focused } \\
\text { coping }\end{array}$} & Escape-avoid & 0.004 & 0.566 & 4 & 2 & 6,8 \\
\hline & Distancing & 0.422 & 0.692 & 4 & 2 & 22,27 \\
\hline & $\begin{array}{l}\text { Positive } \\
\text { reappraisal }\end{array}$ & 0.609 & 0.693 & 4 & 3 & $23,26,31$ \\
\hline & Self control & 0.053 & 0.595 & 4 & 2 & 11,32 \\
\hline & $\begin{array}{l}\text { Accepting } \\
\text { responsibility }\end{array}$ & 0.745 & 0.745 & 4 & 4 & $5,14,17,30$ \\
\hline \multicolumn{2}{|c|}{ Jumlah butir keseluruhan: } & & & 32 & 25 & \\
\hline
\end{tabular}

$\mathrm{N}$ uji coba alat ukur $=34$ orang subyek

Tabel 2. Hasil Reliabilitas Alat Ukur Tipe Kepribadian

\begin{tabular}{|c|c|c|c|c|c|c|}
\hline \multirow{3}{*}{ Dimensi } & \multirow{3}{*}{ Indikator } & \multicolumn{2}{|c|}{ Reliabilitas $(\alpha)$} & \multicolumn{2}{|c|}{ Banyak butir } & \multirow{3}{*}{ Butir yang reliabel } \\
\hline & & Sebelum & Sesudah & Sebelum & Sesudah & \\
\hline & & \multicolumn{2}{|c|}{ Analisis Butir } & \multicolumn{2}{|c|}{ Analisis Butir } & \\
\hline \multirow[t]{7}{*}{ Ekstrovert } & Sosiabilitas tinggi & 0.600 & 0.674 & 6 & 4 & $3,19,27,38$ \\
\hline & Talkative & 0.672 & 0.672 & 6 & 6 & $14,26,28,34,36,40$ \\
\hline & Asertif & 0.590 & 0.649 & 6 & 5 & $9,22,25,31,37$ \\
\hline & Optimis & 0.727 & 0.727 & 6 & 6 & $1,5,11,16,20,42$ \\
\hline & Impulsif & 0.766 & 0.824 & 6 & 5 & $17,21,23,33,39$ \\
\hline & Aktif & 0.564 & 0.632 & 6 & 4 & $6,8,10,35$ \\
\hline & Riang & 0.492 & 0.530 & 6 & 5 & $2,15,18,24,32$ \\
\hline \multicolumn{2}{|c|}{ Jumlah butir keseluruhan: } & & & 42 & 25 & \\
\hline
\end{tabular}

$\mathrm{N}$ uji coba alat ukur $=50$ orang subyek 


\section{ANALISIS \& HASIL}

Subyek dikelompokkan menjadi dua tipe kepribadian yaitu subyek dengan tipe kepribadian ekstrovert dan introvert, sehingga terlebih dahulu dibuat norma persentil dari skor total dimensi ekstrovert. Hasil dari norma persentil diperoleh skor $\mathrm{X}$ minimum 66 ( $\mathrm{cP}=0.5)$ hingga $102(\mathrm{cP}=21.9)$ dikategorikan sangat rendah berarti kelompok tipe kepribadian introvert (kode 1). Skor 124 (cP=77.6) hingga $152(\mathrm{cP}=100)$ dikategorikan sangat tinggi berarti kelompok tipe kepribadian ekstrovert (kode 2).

Berdasarkan norma persentil tersebut, diperoleh sebanyak 42 subyek dengan tipe kepribadian introvert, 50 subyek dengan tipe kepribadian ekstrovert, dan 100 subyek tidak termasuk dalam kategori kepribadian manapun (un-classified). Total dari subyek keseluruhan setelah dilakukan pengelompokkan menjadi 92 subyek.

Pada perempuan dengan tipe kepribadian introvert diperoleh nilai rata-rata $42.14(\mathrm{SD}=7.64)$ untuk dimensi problem focused coping dan nilai rata-rata $37.02(\mathrm{SD}=4.19)$ untuk dimensi emotion focused coping. Pada perempuan dengan tipe kepribadian ekstrovert diperoleh nilai rata-rata sebesar $48.60(\mathrm{SD}=6.69)$ untuk dimensi problem focused coping dan nilai rata-rata $38.02(\mathrm{SD}=4.02)$ untuk dimensi emotion focused coping.

Uji perbedaan pemilihan strategi coping pada perempuan korban pelecehan seksual ditinjau dari tipe kepribadian ini menggunakan Chi-Square crosstabs dengan bantuan SPSS 13.0 for Windows. Sebanyak 92 subyek hasil proses screening, kemudian dicari perbedaan dalam penggunaan strategi coping. Dari hasil pengujian diperoleh hasil untuk tipe kepribadian introvert sebanyak 13 subyek menggunakan strategi problem focused coping dan 8 subyek menggunakan strategi emotion focused coping. Untuk tipe kepribadian ekstrovert sebanyak 16 subyek menggunakan strategi problem focused coping dan 6 subyek menggunakan strategi emotion focused coping. Nilai Chi-Square $\left(\chi^{2}\right.$ hitung $)=0.573$ dan $(\mathrm{df})=1$. Berdasarkan tabel, didapat $\chi^{2}$ tabel adalah 3.84. Oleh karena, $\chi^{2}$ hitung $<\chi^{2}$ tabel $(0.573<3.84)$. Berdasarkan probabilitas, diperoleh sig/p 0.449>0.05, maka Ho diterima yang berarti tidak ada perbedaan dalam penggunaan strategi coping pada perempuan korban pelecehan seksual ditinjau dari tipe kepribadian.

Hasil survei berdasarkan usia terhadap jumlah respon dari bentuk pelecehan seksual yang terdiri atas pelecehan seksual fisik, verbal, dan tertulis.

Tabel 3. Gambaran Data Pelecehan Seksual Fisik, Verbal, dan Tertulis

\begin{tabular}{|c|c|c|c|}
\hline \multicolumn{4}{|c|}{ Bentuk pelecehan } \\
\hline \multirow{2}{*}{ Usia } & Fisik & Verbal & Tertulis \\
\cline { 2 - 4 } & $\mathbf{( \% )}$ & $\mathbf{( \% )}$ & $\mathbf{( \% )}$ \\
\hline $20-24$ & 59.8 & 57.8 & 46.7 \\
\hline $25-29$ & 29.3 & 31.3 & 36 \\
\hline $30-34$ & 7.2 & 6.9 & 9.3 \\
\hline $35-39$ & 2.7 & 2.7 & 5.3 \\
\hline$\geq 40$ & 1.0 & 1.3 & 2.7 \\
\hline Total & 100 & 100 & 100 \\
\hline
\end{tabular}


Tabel 4. Lima Bentuk Pelecehan Fisik Terbanyak pada Perempuan Korban Pelecehan Seksual berdasarkan Usia

\begin{tabular}{|c|c|c|c|c|c|}
\hline \multirow{3}{*}{ Bentuk pelecehan fisik } & \multicolumn{5}{|c|}{ Usia } \\
\hline & $20-24$ & $25-29$ & 30-34 & 35-39 & $\geq 40$ \\
\hline & \multicolumn{5}{|c|}{ Persentase $(\%)$} \\
\hline Laki-laki tersenyum nakal & 7.5 & 3.5 & 9 & 3 & 1 \\
\hline $\begin{array}{l}\text { Laki-laki tidak dikenal mencolek } \\
\text { bagian tubuh }\end{array}$ & 7 & 3 & 0.9 & 0.1 & 0 \\
\hline $\begin{array}{l}\text { Laki-laki tidak dikenal } \\
\text { mengedipkan atau mengerlingkan } \\
\text { mata }\end{array}$ & 6.5 & 3.3 & 0.7 & 0.3 & 0.1 \\
\hline Laki-laki menatap penuh nafsu & 6.1 & 3.3 & 1 & 0.4 & 0.1 \\
\hline $\begin{array}{l}\text { Laki-laki tidak dikenal merapatkan } \\
\text { tubuhnya ke tubuh korban }\end{array}$ & 5.6 & 3.1 & 0.5 & 0.2 & 0.1 \\
\hline
\end{tabular}

Tabel 5. Dua Bentuk Pelecehan Seksual Tertulis pada Perempuan Korban Pelecehan Seksual berdasarkan Usia

\begin{tabular}{|l|c|c|c|c|c|c|}
\hline \multirow{2}{*}{\multicolumn{1}{|c|}{ Bentuk pelecehan tertulis }} & \multicolumn{5}{|c|}{ Usia } \\
\cline { 2 - 7 } & $\mathbf{2 0 - 2 4}$ & $\mathbf{2 5 - 2 9}$ & $\mathbf{3 0 - 3 4}$ & $\mathbf{3 5 - 3 9}$ & $\geq \mathbf{4 0}$ \\
\hline & \multicolumn{6}{|c|}{ Persentase (\%) } \\
\hline Laki-laki memperlihatkan benda atau gambar porno & 34.7 & 21.3 & 5.3 & 2.7 & 1.3 \\
\hline Laki-laki pernah mengirim sms porno & 12 & 14.7 & 4 & 2.7 & 1.3 \\
\hline
\end{tabular}

Tabel 6. Gambaran Data Dampak Psikologis yang Dialami Perempuan Korban Pelecehan Seksual

\begin{tabular}{|l|c|}
\hline \multicolumn{1}{|c|}{ Dampak psikologis } & Persentase (\%) \\
\hline Rasa marah & 28.5 \\
\hline Merasa dihina atau direndahkan & 19.8 \\
\hline Merasa gelisah atau gugup & 18.5 \\
\hline Kecemasan & 10.9 \\
\hline Merasa tercekam atau ketakutan ketika sendirian & 8.0 \\
\hline Tidak berdaya & 3.1 \\
\hline Depresi & 2.9 \\
\hline Menurunnya rasa percaya diri & 2.9 \\
\hline Merasa bersalah & 2.2 \\
\hline Kehilangan kontrol & 2.0 \\
\hline Menurunnya motivasi & 1.1 \\
\hline
\end{tabular}


Tabel 7. Gambaran Data Dampak Fisik yang Dialami Perempuan Korban Pelecehan Seksual

\begin{tabular}{|l|c|}
\hline \multicolumn{1}{|c|}{ Dampak fisik } & Persentase (\%) \\
\hline Sakit kepala & 27.3 \\
\hline Gangguan tidur & 24.8 \\
\hline Mual & 17.6 \\
\hline Berbicara sambil menangis & 12.1 \\
\hline Gangguan makan & 10.9 \\
\hline Gangguan lambung (gastrointestinal) & 3.6 \\
\hline Menurun atau meningkatnya berat badan & 3.6 \\
\hline
\end{tabular}

\section{DISKUSI}

Setelah dilakukan analisis dan pengolahan data, diperoleh hasil kedua tipe kepribadian, yakni introvert dan esktrovert menggunakan kedua strategi coping (problem focused coping dan emotion focused coping), dengan perincian tipe kepribadian introvert sebanyak 13 subyek menggunakan strategi problem focused coping dan 8 subyek menggunakan strategi emotion focused coping. Untuk tipe kepribadian ekstrovert sebanyak 16 subyek menggunakan strategi problem focused coping dan 6 subyek menggunakan strategi emotion focused coping. Hasil menunjukkan tidak ada perbedaan yang signifikan pada pemilihan strategi coping pada perempuan korban pelecehan seksual antara tipe kepribadian ekstrovert dengan perempuan korban pelecehan seksual dengan tipe kepribadian introvert.

Hasil ini menunjukkan bahwa tipe kepribadian seseorang tidak membatasi individu untuk menggunakan strategi coping yang dirasa lebih cocok dengan dirinya. Sebagaimana menurut Lazarus dan Folkman (1984), faktor-faktor lain seperti level ancaman yang dipersepsi seseorang, sumber daya psikologis berupa keterampilan memecahkan masalah, keterampilan social dan dukungan social lebih mempengaruhi penggunaan strategi coping.

Uji perbedaan dari masing-masing indikator problem focused coping diperoleh hasil adanya perbedaan pada indikator-indikatornya yang terdiri dari plan problem solving, confront coping, dan seeking social support antara perempuan korban pelecehan seksual yang memiliki tipe kepribadian ekstrovert dengan tipe kepribadian introvert. Nilai rata-rata pada setiap indikator pada perempuan dengan tipe kepribadian ekstrovert lebih tinggi daripada perempuan dengan tipe kepribadian introvert. Hanya dalam indikator emotion focused coping yaitu self control menunjukkan adanya perbedaan dengan nilai rata-rata pada tipe kepribadian introvert lebih tinggi daripada tipe kepribadian ekstrovert.

Di lain pihak, individu dengan tipe kepribadian introvert memiliki karakteristik pendiam, terkontrol, introspektif, reflektif, jarang berperilaku agresif, tidak mudah hilang kesabaran, tidak menyukai pengambilan keputusan yang impulsif (Posella, 2006; Pervin \& John, 1997). Hal ini sesuai dengan indikator self control yang berarti usaha untuk mengontrol perasaan diri sendiri, menyimpan perasaan dalam diri. Karakteristik dari tipe kepribadian introvert mendukung dalam penggunaan self control.

Pada data tambahan, diperoleh hasil pelecehan seksual yang paling banyak dialami yaitu pelecehan seksual secara fisik pada kategori usia 20-24 tahun sebanyak 59.8\% dan semakin bertambahnya usia pelecehan seksual secara tertulis lebih banyak dialami. Hal ini dapat dilihat pada usia 40 pelecehan seksual tertulis sebanyak $2.7 \%$ paling tinggi diantara pelecehan fisik dan verbal. 


\section{SIMPULAN \& SARAN}

Berdasarkan hasil studi ini, maka dapat disimpulkan bahwa perempuan yang lebih muda mempunyai kecenderungan mendapat perilaku pelecehan seksual secara fisik. Hal ini mungkin disebabkan perempuan lebih muda memiliki sex appeal yang lebih menarik daripada perempuan yang usianya lebih dewasa.

\section{Saran teoretis}

Saran ini ditujukan bagi para praktisi dalam bidang kajian psikologi sosial dan psikologi perempuan dewasa muda. Saran bagi penelitian selanjutnya untuk penelitian secara kuantitatif disarankan menggunakan sampel yang lebih besar, pengambilan sampel hendaknya adalah perempuan yang terbukti telah menjadi korban pelecehan seksual. Pembagian kuesioner dapat diberikan kepada perempuan yang melaporkan kasus pelecehan seksual kepada lembaga khusus yang menangani. Selain itu, penggunaan regresi untuk mengetahui faktor-faktor mana yang paling mempengaruhi penggunaan strategi coping pelecehan seksual.

Selain itu, perlu adanya tambahan secara kualitatif berupa wawancara agar diperoleh data yang lebih mendalam seperti persepsi perempuan korban pelecehan seksual, dinamika coping, sejauh mana pelecehan seksual itu berdampak terhadap fisik dan psikologis yang dirasakan korban terhadap dirinya dan konsekuensi yang dihadapi perempuan korban pelecehan seksual jika melakukan strategi coping tertentu.

\section{Saran praktis}

Saran untuk perempuan korban pelecehan seksual. Beberapa karakteristik dari tipe kepribadian ekstravert mendukung dalam penggunaan strategi problem focused coping seperti sosibilitas tinggi, talkative, riang, optimis, berani, dan asertif. Maka dari itu, saran bagi perempuan ekstravert yang pernah menjadi korban pelecehan seksual diharapkan agar menegur pelaku pelecehan, melakukan tindakan untuk menghentikan perilaku pelecehan seksual terhadap dirinya dan menceritakan atau melaporkan perilaku pelecehan yang dialaminya kepada orang terdekat seperti keluarga, teman, maupun pihak berwenang agar memperoleh solusi penyelesaian masalah. Namun, adapula beberapa karakteristik dari tipe kepribadian yang dapat menjadikan penggunaan strategi coping tidak efektif dalam menghadapi peristiwa pelecehan seksual seperti cenderung agresif dan impulsif. Hal ini dikarenakan pengambilan keputusan yang terburu-terburu dan disertai dengan agresi justru dapat memperburuk situasi. Bagi perempuan intravert yang memiliki karakteristik sosiabilitas rendah, pendiam, penakut, pasif agar dapat bersikap lebih berani, tidak memendam sendiri dan tidak malu dalam menceritakan masalah yang berkaitan dengan peristiwa pelecehan seksual yang pernah dialaminya kepada orang-orang terdekat. Saran ini bertujuan untuk menyelesaikan dan mengurangi dampak psikologis yang dialami, karena strategi coping yang tidak efektif dapat menimbulkan dampak jangka panjang berupa trauma berkepanjangan, depresi, dan ketakutan jika sendirian.

Perempuan juga perlu mengutarakan dampak psikologis dengan berkonsultasi pada psikolog. Selain itu, perempuan perlu mewaspadai situasi-situasi yang memungkinkan terjadinya pelecehan seksual, seperti tidak berjalan sendirian di tempat gelap, memakai busana sopan yang tidak mengundang perilaku pelecehan, menjaga diri baik-baik ketika berada di tempat ramai dan menghindari gerombolan orang yang mungkin dapat melakukan keisengan tertentu. Bagi perempuan yang mengalami perilaku pelecehan seksual terus menerus baik oleh orang yang dikenal maupun yang tidak dikenalnya dan memerlukan bantuan hukum untuk menanganinya dapat melaporkan kasus yang dialaminya kepada Lembaga Bantuan Hukum. 
Saran bagi psikolog. Peran praktisi psikolog diperlukan untuk menangani dampak psikologis akibat dari peristiwa pelecehan seksual. Psikolog perlu menggali persepsi korban pelecehan seksual dan mengkategorikan seberapa serius peristiwa tersebut bagi korban. Dengan mengenali persepsi dari pelecehan seksual tersebut dapat dicari strategi coping yang cocok untuk mengatasinya. Kemudian, jika ada strategi coping yang keliru atau tidak efektif perlu ditelusuri hubungannya dengan tipe kepribadian yang dimiliki oleh korban pelecehan seksual. Pemberian terapi dapat diberikan kepada korban jika diperlukan. Salah satu model terapi yang dapat dilakukan seperti terapi kelompok, dengan mengumpulkan perempuan korban pelecehan seksual dalam satu tempat untuk saling bercerita dan memberi solusi mengenai dampak negatif yang dirasakan.

\section{DAFTAR PUSTAKA}

Abidin, L., \& Suyasa, P. T. Y. S. (2003). Perbedaan penguasaan tugas perkembangan antara remaja yang memiliki tipe kepribadian ekstravert dan remaja yang memiliki tipe kepribadian introvert. Jurnal Phronesis, 5, 93-110.

Alwi., Lapoliwa, H., Sugono, D., Kridalaksana, H., Adiwimarta, S., Suratman, S., Nainggolan, D., Sutiman., Murniah, D., Patoni, A., Burhabudin, E., Gaffar, A., Hanid, A., Haryanto \& Sutini. (2003). Kamus besar bahasa Indonesia edisi ketiga. Jakarta: Balai Pustaka.

Folkman S., Lazarus, R. S., Dunkel-Schetter, C., DeLongis. A., \& Gruen. R.J. (1986). Dynamics od a stressful encpunter: Cognitive appraisal, coping and encounter outcomes. Journal of Personality and Social Psychology, 50, 992-1003.

Hurlock, E. B. (1998). Psikologi perkembangan: Suatu pendekatan sepanjang rentang kehidupan (Istiwidayanti \& Soedjarwo, Penerj.). Jakarta: Erlangga.

Lazarus, R. S. (1976). Patterns of adjustment (3rd ed.). New York: MacGraw-Hill.

Lazarus, R. S., \& Folkman, S. (1984). Stress, appraisal, and coping. New York: Springer Publishing Company.

Pervin, L. A. (1996). The science of personality (1st ed.). New York: John Wiley \& Sons.

Pervin, L. A., \& John, O. P. (1997). Personality: Theory and research (7th ed.). New York: John Wiley $\&$ Sons.

\section{Internet:}

Abdullah, I., Dzuhayatin, S. R., Pitaloka, D. (8 November 2001). Bias gender dalam penanganan kasus kekerasan terhadap perempuan secara ligitatif. Retrieved 19 September 2006, from http://72.14.235.104/search?q=cache:KrZAnuQKWDEJ:www.cpps.or.id/new/seminar/S306.p $\mathrm{df}+$ survey+laporan + pelecehan + seksual\&hl=id\&gl=id\&ct=clnk\&cd=24.

Kusmana, G. (2005). Pelecehan seksual di tempat kerja (Kondisi di Indonesia dan cara mengatasinya). Retrieved 20 September 2006, from http://www.nakertrans.go.id/majalah_buletin/info_hukum/ vol1_vi_2005/pelecehan_seksual.php.

Kusmana, G. (2005). Pelecehan seksual di tempat kerja (Kondisi di Indonesia dan cara mengatasinya). Diunduh 20 September 2006, dari http://www.nakertrans.go.id/majalah_buletin/info_hukum/ vol1_vi_2005/pelecehan_seksual.php. 
Papu, J. (2002). Pelecehan seksual di tempat kerja. Retrieved 4 September 2006, from http://www.epsikologi.com/seks.htm

Posella, D. (2006). Coping styles used by introverts and extroverts in varying stress situations. Retrieved 8 September 2006, from http://web.sbu.edu/psychology/lavin/daniella.htm.

\section{Surat Kabar:}

Swasti, A., Pasaribu, N., \& Gusman, Y. (2006, July 20). Pelecehan seksual tidak bisa dianggap remeh. Kompas, p. 42. 